ARTICLE

\title{
Selective and low temperature transition metal intercalation in layered tellurides
}

Takeshi Yajima ${ }^{1, \dagger}$, Masaki Koshiko ${ }^{1}$, Yaoqing Zhang ${ }^{1}$, Tamio Oguchi ${ }^{2,3}$, Wen Yu ${ }^{1}$, Daichi Kato ${ }^{1}$, Yoji Kobayashi ${ }^{1}$ Yuki Orikasa ${ }^{4}$, Takafumi Yamamoto1, Yoshiharu Uchimoto ${ }^{4}$, Mark A. Green ${ }^{5}$ \& Hiroshi Kageyama ${ }^{1,3}$

Layered materials embrace rich intercalation reactions to accommodate high concentrations of foreign species within their structures, and find many applications spanning from energy storage, ion exchange to secondary batteries. Light alkali metals are generally most easily intercalated due to their light mass, high charge/volume ratio and in many cases strong reducing properties. An evolving area of materials chemistry, however, is to capture metals selectively, which is of technological and environmental significance but rather unexplored. Here we show that the layered telluride $T_{2} \mathrm{PTe}_{2}(T=\mathrm{Ti}, \mathrm{Zr}$ ) displays exclusive insertion of transition metals (for example, $\mathrm{Cd}, \mathrm{Zn}$ ) as opposed to alkali cations, with tetrahedral coordination preference to tellurium. Interestingly, the intercalation reactions proceed in solid state and at surprisingly low temperatures (for example, $80^{\circ} \mathrm{C}$ for cadmium in $\mathrm{Ti}_{2} \mathrm{PTe}_{2}$ ). The current method of controlling selectivity provides opportunities in the search for new materials for various applications that used to be possible only in a liquid.

\footnotetext{
${ }^{1}$ Department of Energy and Hydrocarbon Chemistry, Graduate School of Engineering, Kyoto University, Nishikyo-ku, Kyoto 615-8510, Japan. ${ }^{2}$ Institute of Scientific and Industrial Research, Osaka University, Ibaraki, Osaka 567-0047, Japan. ${ }^{3}$ CREST, Japan Science and Technology Agency (JST), Chiyoda-ku, Tokyo 102-0076, Japan. ${ }^{4}$ Graduate School of Human and Environmental Studies, Kyoto University, Sakyo-ku, Kyoto 606-8501, Japan. ${ }^{5}$ School of Physical Sciences, University of Kent, Canterbury, Kent CT2 7NH, UK. †Present address: Institute for Solid State Physics, The University of Tokyo, Kashiwa,

Chiba 277-8581, Japan. Correspondence and requests for materials should be addressed to H.K. (email: kage@scl.kyoto-u.ac.jp).
} 
ntercalation compounds allow incorporation or exchange of foreign atoms or molecules into the voids of various topologies in the host lattices such as cages (zeolites and so on) ${ }^{1}$, channels (h- $\mathrm{WO}_{3}$ and so on) ${ }^{2}$ and two-dimensional (2D) spaces (graphite and so on $)^{3}$ and represent an important frontier in solid state chemistry. The structural diversity of these solids gives rise to a vast array of applications too extensive to summaries. However, two key areas of particular note are those materials serving as reservoirs to store and release alkali metal ions, for example, $\mathrm{Li}^{+}$for high performance for energy storage devices ${ }^{4}$ and the tuning of exotic superconductivity in $\mathrm{Na}_{x} \mathrm{CoO}_{2} \cdot 1.3 \mathrm{H}_{2} \mathrm{O}$, $\mathrm{Li}_{x}(\mathrm{THF})_{y} \mathrm{HfNCl}$ (THF, tetrahydrofuran) and $\mathrm{Cu}_{x} \mathrm{Bi}_{2} \mathrm{Se}_{3}$ upon intercalation ${ }^{5-7}$

The rich intercalation chemistry that has been discovered for layered materials with van der Waals (vdW) interactions, which includes $\mathrm{V}_{2} \mathrm{O}_{5}, M \mathrm{NCl}(M=\mathrm{Ti}, \mathrm{Zr}), M X_{2}(M=\mathrm{Ti}, \mathrm{Zr}$, Ta and so on; $X=\mathrm{S}, \mathrm{Se}), \mathrm{MPX}_{3}(M=\mathrm{Mg}, \mathrm{Fe}, \mathrm{Ni}$ and so on; $X=\mathrm{S}, \mathrm{Se}), \mathrm{MoS}_{2}$ and $\operatorname{MOX}(M=\mathrm{Ti}, \mathrm{V}, \mathrm{Fe} \text { and so on; } X=\mathrm{Cl}, \mathrm{Br})^{8-12}$, yields various chemical and physical properties. Rather weak interlayer $(\mathrm{vdW})$ interactions and a flexible interlayer spacing allows for incorporation of not only the lowest charged small alkali metal cations, but also many other heavier metals in the periodic table. For instance, $\mathrm{TaS}_{2}$ is capable of intercalating alkali metals, alkali earth metals and nearly all $3 d$ transition metals as well as organic amines ${ }^{13-19}$. However, the poor selectivity in these materials hinders the preferential sorption of heavy metals, which is of environmental significance in the remediation of important toxic heavy metals pollutants, such as $\mathrm{Cd}, \mathrm{Pb}$ and $\mathrm{Hg}^{20}$. Traditional absorbents and ion-exchangers like activated carbon, clays and zeolites also suffer from this problem ${ }^{21-23}$.

Recently, Kanatzidis and colleagues have demonstrated that several layered sulfides exhibit highly selective ion-exchange properties for $\mathrm{Sr}, \mathrm{Hg}, \mathrm{Pd}$ and $\mathrm{Cd}$ within $\mathrm{K}_{2 x} \mathrm{Mn}_{x} \mathrm{Sn}_{3-x} \mathrm{~S}_{6}$ $(0.5<x<0.95$; refs 24,25$)$ and $\mathrm{Cs}$ within $\left[\left(\mathrm{CH}_{3}\right)_{2} \mathrm{NH}_{2}\right]_{2} \mathrm{Ga}_{2} \mathrm{Sb}_{2} \mathrm{~S}_{7}$ $\cdot \mathrm{H}_{2} \mathrm{O}$ (ref. 26), via an aqueous solutions with excess lighter alkali metal ions and protons. In both systems, the high selectivity is ascribed to the favourable interactions between the soft Lewis base $\mathrm{S}^{2-}$ ions of the host layer and the soft Lewis acid of the metal ions as a guest. In this study, we utilize the smaller electronegativity of tellurium to provide a softer Lewis base, compared with $\mathrm{O}, \mathrm{S}$ and $\mathrm{Se}^{27}$, within the layered tellurides, $\mathrm{Ti}_{2} \mathrm{PTe}_{2}$ and $\mathrm{Zr}_{2} \mathrm{PTe}_{2}$, which we expect will promote a higher degree of covalency to selectively bind heavy metals. Prior intercalation studies are largely confined to binary tellurides such as $\mathrm{TiTe}_{2}, \mathrm{ZrTe}_{2}$ and $\mathrm{IrTe}_{2}$, with a primary interest in superconductivity and ferromagnetism ${ }^{28,29}$. The structure of $\mathrm{T}_{2} \mathrm{PTe}_{2}(T=\mathrm{Ti}, \mathrm{Zr})$ is built up of slabs of hexagonal closedpacked triple Te-P-Te layers with $T$ atom being octahedrally coordinated by three Te and three P atoms (see Fig. 1a) ${ }^{30,31}$. The individual slabs are stacked such that a rhombohedral structure is formed. It is isostructural with 3R-type $\mathrm{Ta}_{2} \mathrm{CS}_{2}$ (ref. 32). The absence of metal species between the double $\mathrm{Te}$ layers suggests relatively weak interlayer interactions and thus intercalation chemistry.

Herein, we show that $T_{2} \mathrm{PTe}_{2}$ displays exclusive insertion of transition metals of $\mathrm{Cu}, \mathrm{Zn}$ and $\mathrm{Cd}$ with tetrahedral coordination preference to tellurium. The intercalation reactions proceed in solid state and at surprisingly low temperatures-as low as $80^{\circ} \mathrm{C}$ for cadmium in $\mathrm{Ti}_{2} \mathrm{PTe}_{2}$ and $70^{\circ} \mathrm{C}$ for copper in $\mathrm{Zr}_{2} \mathrm{PTe}_{2}$. The metal intercalation induces a structural transition involving the change in stacking sequence from the 3R- to the 1T-type. Our first-principles calculations demonstrate a unique band structure with a pseudogap just above the Fermi energy, implying that the selective intercalation originates predominantly from the thermodynamic stabilization of the intercalated phase. The observed low temperature solution-free metal capturing, together with the reversible reaction enabling separation of hazardous metal from a powder metal mixture or an alloy, suggest potential applicability of our materials in environmental remediation.

\section{Results}

Metal intercalation and structural characterization. We tested a series of alkali, alkali earth, transition and post-transition metals $(M)$ for their intercalation properties into $\mathrm{Ti}_{2} \mathrm{PTe}_{2}$. The reactions were typically conducted by heating a pelletized mixture of $\mathrm{Ti}_{2} \mathrm{PTe}_{2}$ and $M$ in vacuum at temperatures up to $400{ }^{\circ} \mathrm{C}$ (see the 'Methods' section for a detailed synthesis procedure). Powder X-ray diffraction patterns collected on the samples after attempted intercalation revealed little or no intercalation in most cases, including alkali metals, as summarized in Supplementary Fig. 1. These reactions either lead to decomposition of $\mathrm{Ti}_{2} \mathrm{PTe}_{2}$ or no reaction was observed. In contrast, $\mathrm{Zn}, \mathrm{Cu}$ and $\mathrm{Cd}$ readily intercalated. $\mathrm{Fe}$ and $\mathrm{Mn}$ intercalation occurred only at high temperature $\left(400^{\circ} \mathrm{C}\right)$, yet leaving a large amount of $\mathrm{Ti}_{2} \mathrm{PTe}_{2}$ unreacted (Supplementary Fig. 2). $\mathrm{Zr}_{2} \mathrm{PTe}_{2}$ shows the same reaction result, except the fact that no intercalation was observed for Fe and Mn (Supplementary Fig. 1).

As a representative example, we first show the intercalation of $\mathrm{Zn}$ into $\mathrm{Ti}_{2} \mathrm{PTe}_{2}$. The product prepared at $300^{\circ} \mathrm{C}$ for $48 \mathrm{~h}$ with a $\mathrm{Zn} / \mathrm{Ti}_{2} \mathrm{PTe}_{2}$ molar ratio $(p)$ of 0.4 exhibits a similar X-ray diffraction profile to the parent phase (Fig. 2). However, a close inspection of the pattern shows a significant shift of the $(00 l)$ reflections. Moreover, a clear change in stacking sequence from the rhombohedral to a primitive cell is evident from the appearance of new characteristic reflections. Here, the lattice constants for the precursor $(\mathrm{R})$ and product $(\mathrm{P})$ phases are correlated by the relation: $a_{\mathrm{P}} \approx a_{\mathrm{R}}, 3 c_{\mathrm{P}} \approx c_{\mathrm{R}}$. The clear expansion of the normalized $c$ axis $\left(c_{\mathrm{P}}-c_{\mathrm{R}} / 3=0.348 \AA\right)$ suggests successful intercalation of $\mathrm{Zn}$, presumably between the double Te layers. As shown in Supplementary Fig. 3, energy dispersive X-ray spectroscopy (EDX) measurements show that the $\mathrm{Zn}$ content is approximately $x \approx 0.36(5)$ (in $\mathrm{Zn}_{x} \mathrm{Ti}_{2} \mathrm{PTe}_{2}$ ). The identical Bravais lattice change from $\mathrm{R}$ to $\mathrm{P}$ along with the elongated normalized $c$ parameter is also observed for $\mathrm{Cd}$ (Fig. 2), $\mathrm{Cu}, \mathrm{Fe}$ and $\mathrm{Mn}$ in $\mathrm{Ti}_{2} \mathrm{PTe}_{2}$ (Supplementary Fig. 2), and $\mathrm{Cd}, \mathrm{Zn}$ and $\mathrm{Cu}$ in $\mathrm{Zr}_{2} \mathrm{PTe}_{2}$ (Supplementary Fig. 4). We note that $\mathrm{Fe}$ and $\mathrm{Mn}$ intercalated phases for $T=\mathrm{Ti}$ were not obtained as a single phase, but together with a large amount of unreacted $\mathrm{Ti}_{2} \mathrm{PTe}_{2}$. The lattice parameters of the precursor and the intercalated compounds are shown in Table 1 and the results of elemental analysis by SEM/ EDX are shown in Supplementary Figs 5 and 6.

For a more precise structural characterization of $\mathrm{Zn}_{x} \mathrm{Ti}_{2} \mathrm{PTe}_{2}$, synchrotron X-ray diffraction and neutron diffraction Rietveld refinements were carried out. Here, we recall that $\mathrm{Ta}_{2} \mathrm{CS}_{2}$ has two polymorphs with different stacking sequences, the 3R-type $(R-3 m)$ being isostructural with $\mathrm{Ti}_{2} \mathrm{PTe}_{2}$ and the 1T-type $(P-3 m 1)$, as displayed in Fig. 1a,b, respectively ${ }^{33}$. Both forms of $\mathrm{Ta}_{2} \mathrm{CS}_{2}$ are capable of accepting various foreign cations, but since the stacking sequences are different, intercalated cations find themselves in different coordination environments. For example, $\mathrm{Fe}$ and $\mathrm{Co}$ in $3 \mathrm{R}-M_{x} \mathrm{Ta}_{2} \mathrm{CS}_{2}(M=\mathrm{Fe}, \mathrm{Co})$ partially occupy octahedral voids (site $6 c$ ), whereas $\mathrm{Cu}$ in $1 \mathrm{~T}-M_{x} \mathrm{Ta}_{2} \mathrm{CS}_{2}$ occupies tetrahedral voids (site $2 d)^{33-35}$, as illustrated in Supplementary Fig. 7. Given the observed unit cell change in $\mathrm{Ti}_{2} \mathrm{PTe}_{2}$ upon $\mathrm{Zn}$ intercalation, it is likely that $\mathrm{Zn}_{x} \mathrm{Ti}_{2} \mathrm{PTe}_{2}$ also adopts the $1 \mathrm{~T}-\mathrm{Cu}_{x} \mathrm{Ta}_{2} \mathrm{CS}_{2}$ structure. Therefore, this structure was adopted as a starting model for a Rietveld refinement, by placing $\mathrm{Zn}$ at the $2 d$ $(1 / 3,2 / 3, z)$ site (Fig. 1b,d). The synchrotron pattern also shows minor impurities, $\mathrm{TiP}$ and $\mathrm{ZnTe}$, which were included in the refinement. The refinements converged comfortably with $R_{\mathrm{wp}}=7.51 \%$ and $R_{\mathrm{p}}=5.20 \%$ for synchrotron X-ray diffraction 
a

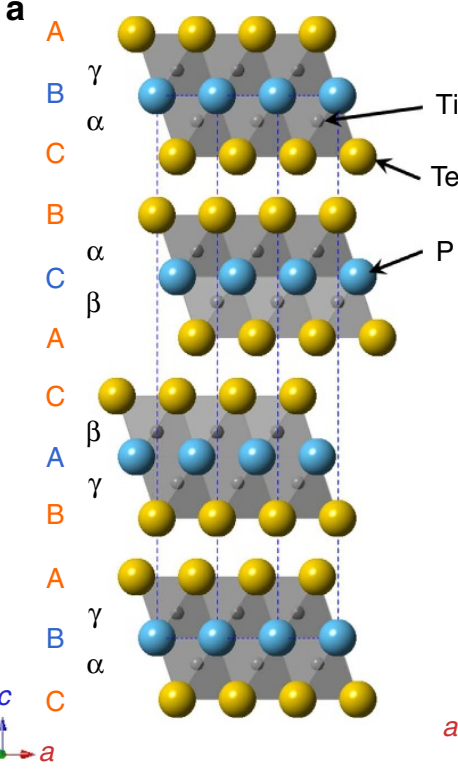

b

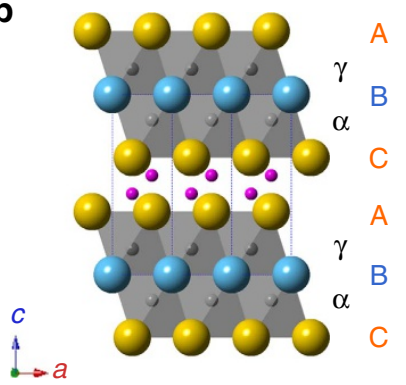

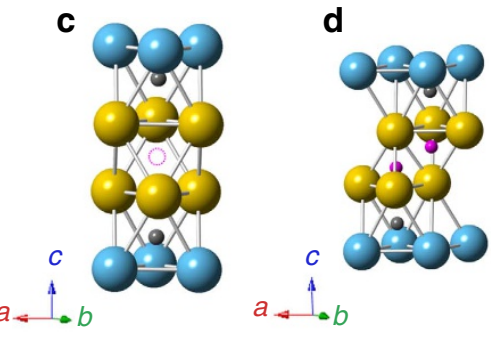

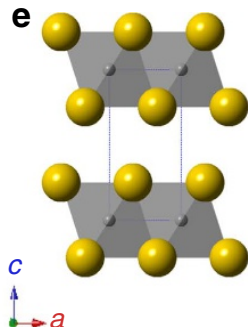

Figure 1 | Crystal structures of $\mathbf{T}_{\mathbf{2}} \mathbf{P T e} \mathbf{2}(\boldsymbol{T}=\mathbf{T i}$ and $\mathbf{Z r})$ and their intercalated derivative. (a) $T_{2} \mathrm{PTe} \mathrm{e}_{2}\left(3 \mathrm{R}-\mathrm{Ta}_{2} \mathrm{CS}_{2}\right.$ type with space group $\left.R-3 m\right)$ and (b) metal-intercalated $M_{x} T_{2} \mathrm{PTe}_{2}$ (1T-Ta $\mathrm{CS}_{2}$ type with space group $\left.\mathrm{P}-3 \mathrm{~m} 1\right)$, where black, blue, yellow and purple spheres, respectively denote Ti/Zr, $\mathrm{P}$, Te and $M$ atoms. A, B, C are used to represent anion (Te, P) stacking arrangement, while $\alpha, \beta, \gamma$ represent the Ti/Zr stacking sequence. The unit cells are shown by the dotted lines. (c) Coordination environment around an octahedral void (dotted circle) in the 3R structure. (d) Coordination environment around a tetrahedral void in the $1 T$ structure. In $M_{x} T_{2} \mathrm{PTe}_{2}$, the voids are partially occupied by $M$ (for example, $\sim 20 \%$ for $Z n$ ). (e) Crystal structure of TiTe and $M X_{2}$ compounds in general $(M=T i, Z r$, Ta and so on; $X=S, S e)$.

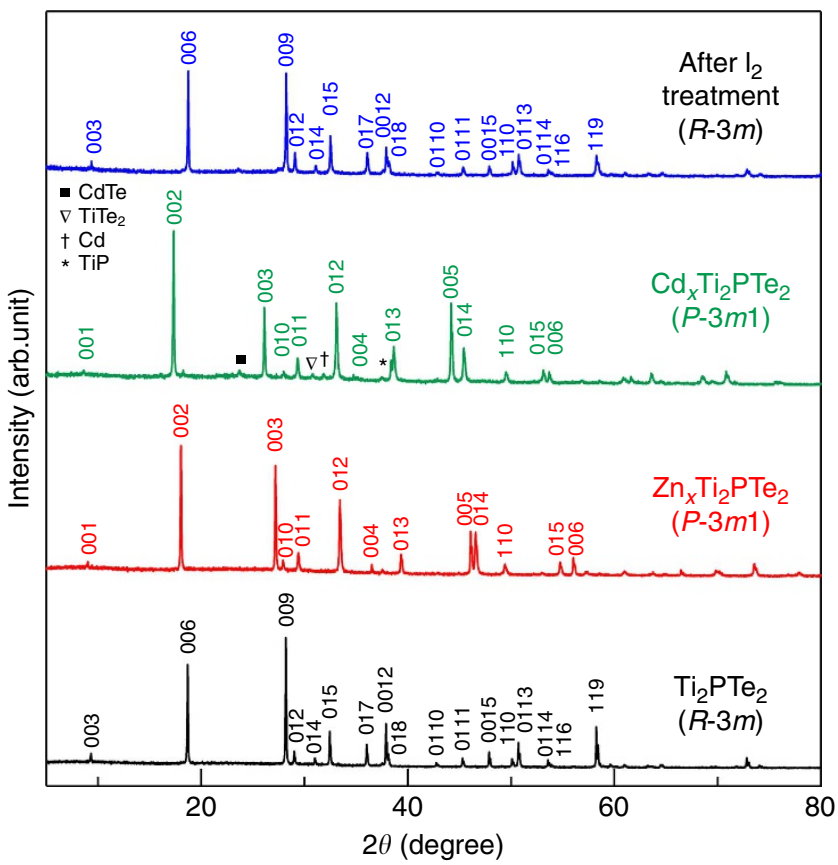

Figure 2 | X-ray diffraction patterns of $\mathrm{Ti}_{2} \mathrm{PTe}_{\mathbf{2}}$ and (de)intercalated materials. From bottom to top: $\mathrm{Ti}_{2} \mathrm{PTe}_{2}, \mathrm{Zn}_{x} \mathrm{Ti}_{2} \mathrm{PTe}_{2}\left(300^{\circ} \mathrm{C}, 48 \mathrm{~h}, p=0.4\right)$, $\mathrm{Cd}_{x} \mathrm{Ti}_{2} \mathrm{PTe}_{2}\left(200^{\circ} \mathrm{C}, 48 \mathrm{~h}, p=0.4\right)$, deintercalated product after $\mathrm{I}_{2}$ treatment of $\mathrm{Zn}_{x} \mathrm{Ti}_{2} \mathrm{PTe}_{2}$ at room temperature. Peaks with symbols show tiny amount of impurity phases ( $\mathrm{CdTe}, \mathrm{TiTe}_{2}$ and so on) for $\mathrm{Cd}$ intercalation.

and $R_{\mathrm{wp}}=6.36 \%$ and $R_{\mathrm{p}}=4.95 \%$ for neutron diffraction (see Fig. 3a,b and Supplementary Table 1). The refined $\mathrm{Zn}$ composition of $x=0.40$ is close to the value obtained from the EDX measurements. Placing $\mathrm{Zn}$ at the octahedral $1 b$ site (Supplementary Fig. 7) did not lead to better convergence.
Likewise, the synchrotron $\mathrm{X}$-ray diffraction refinement for $\mathrm{Cu}_{x} \mathrm{Ti}_{2} \mathrm{PTe}_{2}, \quad \mathrm{Zn}_{x} \mathrm{Zr}_{2} \mathrm{PTe}_{2}$ and $\mathrm{Cd}_{x} \mathrm{Zr}_{2} \mathrm{PTe}_{2}$ revealed the occupation of $\mathrm{Cu}, \mathrm{Zn}$ and $\mathrm{Cd}$ at the tetrahedral $(2 d)$ site and a composition of $x=0.282(2), 0.337(6)$ and 0.194(5) (Fig. 3d, Supplementary Fig. 8 and Supplementary Table 2).

For $\mathrm{Ti}_{2} \mathrm{PTe}_{2}$, the refined atomic coordinate $z$ for $M$ is slightly different between $\mathrm{Zn}$ and $\mathrm{Cu}$. The $\mathrm{Cu}$ position $(z=0.452)$ is nearly at the centre of the $\mathrm{Te}_{4}$ tetrahedron. In contrast, the $\mathrm{Zn}$ position $(z=0.4347)$ is slightly off-centred as found in $1 \mathrm{~T}-\mathrm{Cu}_{x} \mathrm{Ta}_{2} \mathrm{CS}_{2}$ (ref. 34), giving $\mathrm{Zn}-\mathrm{Te}$ distances of $2.287 \AA(\times 1)$ and $2.517 \AA(\times 3)$. The former value is shorter than those of common phases such as $\mathrm{ZnTe}(2.643 \AA)$ and $\mathrm{ZnAl}_{2} \mathrm{Te}_{4}$ (2.578 ; refs 36,37$)$. This is rather curious, but a number of techniques support this observation. The charge density distributions around $\mathrm{Zn}$ obtained by a MEM analysis shows a strong covalent $\mathrm{Zn}-\mathrm{Te}$ bond (due to the smaller electronegativity of tellurium), indicative of the single short $\mathrm{Zn}-\mathrm{Te}$ distance (Fig. 3a). Extended X-ray absorption fine structure analysis at the $\mathrm{Zn} \mathrm{K}$-edge (Fig. 3c, Supplementary Fig. 9 and Supplementary Table 3) also led to a better fit with the Rietveld structure incorporating the long/short $\mathrm{Zn}-\mathrm{Te}$ bonds, as opposed to an isotropic model where all four $\mathrm{Zn}-\mathrm{Te}$ bonds are the same length. The octahedral model ( $\mathrm{Zn}$ at the $1 d$ site) also failed to reproduce the experimental data. The off-centring of $\mathrm{Zn}$ may arise to reduce repulsion from the $\mathrm{Ti}$ located on the top of Zn (see Fig. 1d).

The reversibility of the intercalation process is demonstrated by regeneration of the original $\mathrm{Ti}_{2} \mathrm{PTe}_{2}$ host upon exposure to $\mathrm{I}_{2}$ in acetonitrile at room temperature, as determined by X-ray diffraction (Fig. 2). The $I_{2}$ reaction gives rise to extra tiny peaks such as at $27.8^{\circ}$, which can be attributed to Te metal. This possibly results from the decomposition of $\mathrm{ZnTe}$, a tiny impurity phase already present in $\mathrm{Ti}_{2} \mathrm{PTe}_{2}$. For the initial $\mathrm{Zn}$ intercalation, we further examined the reaction products while varying the $\mathrm{Zn} / \mathrm{Ti}_{2} \mathrm{PTe}_{2}$ molar ratio $p(0.1 \leq p \leq 0.5)$, with a fixed reaction temperature and time $\left(300^{\circ} \mathrm{C}, 48 \mathrm{~h}\right)$. For $p=0.1$, the $3 \mathrm{R}$ phase coexists with traces of the $1 \mathrm{~T}$ phase. With increasing $p$, 
the amount of the latter phase increases, whereas the former decreases, and the lattice constants of the rhombohedral phase do not change (Supplementary Fig. 10). In other words, there is no uptake of guest ions in the original $3 \mathrm{R}$ phase and $\mathrm{Zn}$ intercalation readily induces structural transition and the phase separation. This has been confirmed by SEM/EDX results (Supplementary Fig. 3).

Theoretical calculations. As discussed above, upon intercalation $3 \mathrm{R}-\mathrm{T}_{2} \mathrm{PTe}_{2}$ transforms to the $1 \mathrm{~T}$ polytype, and metals amenable to intercalation $(\mathrm{Cd}, \mathrm{Zn}, \mathrm{Cu}, \mathrm{Fe}, \mathrm{Mn}$ for $\mathrm{T}=\mathrm{Ti}$ and $\mathrm{Cd}, \mathrm{Zn}$, $\mathrm{Cu}$ for $T=\mathrm{Zr}$ ) are less electropositive and favour tetrahedral coordination with $\mathrm{Te}^{38}$. However, no intercalation of alkali metals

\begin{tabular}{|c|c|c|c|c|}
\hline \multirow{2}{*}{$\frac{T}{M}$} & \multicolumn{2}{|c|}{$\mathbf{T i}$} & \multicolumn{2}{|c|}{$\mathrm{Zr}$} \\
\hline & $a(\AA)$ & $c(\AA)$ & $a(\AA)$ & $c(\AA)$ \\
\hline Parent phase & $3.6393(2)$ & $\star \star 9.4951$ (4) & $3.8142(3)$ & ${ }^{\star \star} 9.7271(6)$ \\
\hline $\mathrm{Zn}$ & $3.6917(4)$ & $9.8480(7)$ & $3.85873(7)$ & $10.1664(1)$ \\
\hline $\mathrm{Cu}$ & $3.6726(4)$ & $9.7822(7)$ & $3.8445(2)$ & $10.1082(5)$ \\
\hline $\mathrm{Cd}$ & $3.6806(6)$ & $10.238(1)$ & $3.8469(2)$ & $10.4197(4)$ \\
\hline${ }^{\star} \mathrm{Fe}$ & $3.6356(4)$ & 9.639 (1) & NA & NA \\
\hline${ }^{\star} \mathrm{Mn}$ & $3.648(2)$ & $9.628(4)$ & NA & NA \\
\hline
\end{tabular}

The values are received from the LeBail analysis of laboratory synchrotron $\mathrm{X}$-ray diffraction patterns which are shown in Fig. 2, Supplementary Figs 2 and 4 . $\mathrm{Fe}_{x} \mathrm{Ti}_{2} \mathrm{PTe}_{2}$ and $\mathrm{Mn}_{x} \mathrm{Ti}_{2} \mathrm{PTe}_{2}$ were yielded together with a large amount of unreacted $\mathrm{Ti}_{2} \mathrm{PTe}_{2}$. ${ }^{\star}{ }^{*} \mathrm{For}_{2} \mathrm{~T}_{2} \mathrm{PTe}_{2}$ with the $3 \mathrm{R}$ structure, the normalized $c$ constant $(c / 3)$ is shown for the sake of comparison. NA, not available. was observed. Such intercalation selectivity in $\mathrm{Ti}_{2} \mathrm{PTe}_{2}$ is quite unprecedented and clearly different from other layer materials based on oxide, sulphide and chloride with weaker interlayer vdW bonding, such as $\mathrm{V}_{2} \mathrm{O}_{5}, M \mathrm{NCl}, M X_{2}(X=\mathrm{S}, \mathrm{Se})$ and $M P X_{3}$ $(X=\mathrm{S}, \mathrm{Se})^{8-11}$. Apparently, the use of less electronegative $\mathrm{Te}$ layers (versus $\mathrm{O}, \mathrm{S}, \mathrm{Se}$ and so on) hampers alkali metals intercalation. Interestingly, the related telluride $\mathrm{TiTe}_{2}$ is known to accommodate $\mathrm{Li}$ and $\mathrm{Rb}$, together with transition metals ${ }^{28,39-42}$. Namely, the intercalation selectivity of $\mathrm{TiTe}_{2}$ and $\mathrm{ZrTe}_{2}$ can be greatly enhanced by $\mathrm{Ti}_{2} \mathrm{PTe}_{2}$ and $\mathrm{Zr}_{2} \mathrm{PTe}_{2}$. This clear difference in intercalativity may originate from the difference in crystal structure and electronic structure. Compared with the structure of $\mathrm{TTe}_{2}$ having $\mathrm{TTe}_{6}$ octahedra (Fig. 1e), $\mathrm{T}_{2} \mathrm{PTe}_{2}$ possesses an additional $\mathrm{P}$ layer, thus providing an anisotropic octahedral coordination of $\mathrm{TTe}_{3} \mathrm{P}_{3}$ (Fig. 1a,b). An additional notable feature in $T_{2} \mathrm{PTe}_{2}$-being distinct from $\mathrm{TTe}_{2}$ and other intercalation materials with vdW layers-is the presence of one extra electron per formula in the conduction band, which is described by the nominal charge configuration: $\left(T^{4+}\right)_{2}\left(\mathrm{P}^{3-}\right)\left(\mathrm{Te}^{2-}\right)_{2}\left(\mathrm{e}^{-}\right)$, though this and intercalated compounds are basically covalent in nature. This is evidenced by $\mathrm{X}$-ray absorption near edge structure (XANES) results showing the $\mathrm{Ti}^{4+}$ state and fairly good metallic conductivity $(\rho=40 \mu \Omega)$ at room temperature ${ }^{31}$.

Calculations based on density functional theory have revealed unique features in the electronic structures and bonding character of this material. The results show that $3 \mathrm{R}-\mathrm{Ti}_{2} \mathrm{PTe}_{2}$ is indeed metallic with a nearly half-filled electron Fermi surface, as illustrated in Fig. 4 and Supplementary Fig. 11. This metallic feature is in sharp contrast to $\mathrm{TiTe}_{2}$, where hole and electron Fermi surfaces are compensated and a semimetallic-like electronic state is realized ${ }^{43}$. Despite the two-dimensional

C
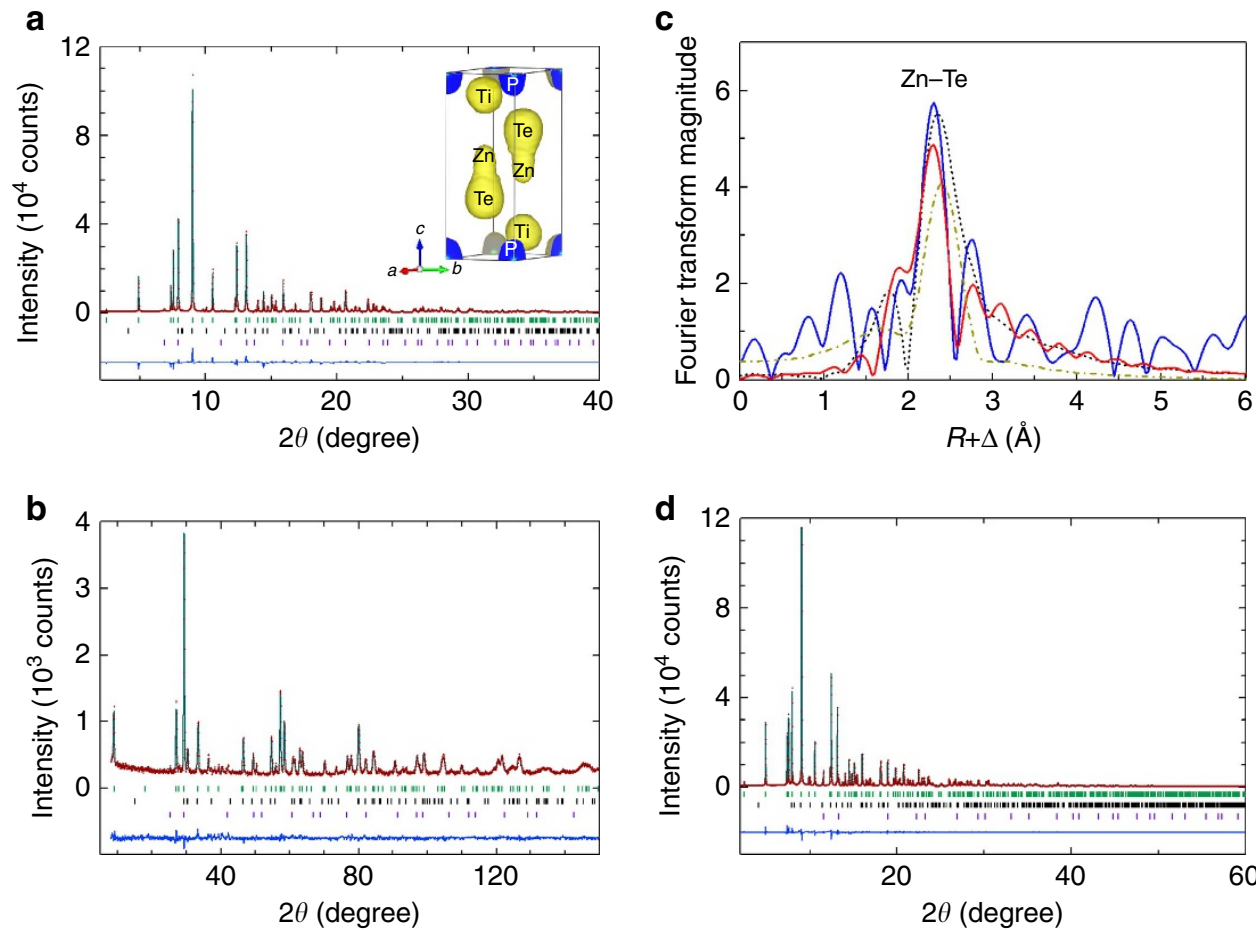

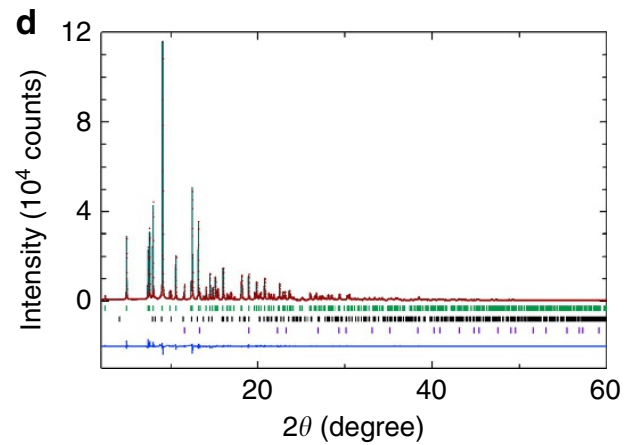

Figure 3 | Structural refinement for $\mathbf{M}_{\mathbf{x}} \mathbf{T i}_{\mathbf{2}} \mathbf{P T} \mathbf{T}_{\mathbf{2}}(\mathbf{M}=\mathbf{Z n}, \mathbf{C u})$. Refined (a) Synchrotron X-ray diffraction and (b) neutron diffraction patterns of $\mathrm{Zn}_{0.4} \mathrm{Ti}_{2} \mathrm{PTe}_{2}$, showing observed (red), calculated (green) and difference (blue) profiles. The upper, middle and lower ticks represent the positions of the calculated Bragg reflections of $\mathrm{Zn}_{0.4} \mathrm{Ti}_{2} \mathrm{PTe} \mathrm{e}_{2}$ TiP and $\mathrm{ZnTe}$, respectively. Inset of a shows the result of MEM analysis, where a strong $\mathrm{Zn}$-Te bond along the $\mathrm{c}$

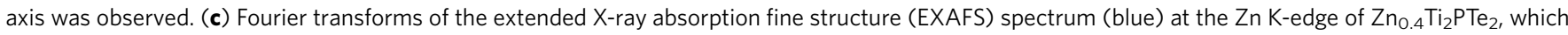
is compared with calculated Fourier transforms of (red) the anisotropic tetrahedron based on the neutron diffraction refined crystal structure, (dotted line) the equidistant tetrahedron and (dashed line) octahedron. (d) Refined synchrotron X-ray diffraction pattern of $\mathrm{Cu}_{0.28} \mathrm{Ti}_{2} \mathrm{PTe}_{2}$. The upper, middle and lower ticks represent the positions of the calculated Bragg reflections of $\mathrm{Cu}_{0.28} \mathrm{Ti}_{2} \mathrm{PTe}_{2}$, $\mathrm{TiP}$ and $\mathrm{Cu}$, respectively. 
crystal structure in $\mathrm{Ti}_{2} \mathrm{PTe}_{2}$, the Fermi surface has a threedimensionally deformed shape (Supplementary Fig. 11b) and the estimated Fermi velocity is $v_{x}=2.70 \times 10^{7} \mathrm{~cm} \mathrm{~s}^{-1}$ and $v_{z}=1.83 \times 10^{7} \mathrm{~cm} \mathrm{~s}^{-1}$, giving rise to a rather small anisotropy $\left(v_{z} / v_{x}\right)=0.68$. States around the Fermi energy consist mainly of Ti $d$ orbitals hybridized with Te $p$ orbitals, as found in the partial density of states (DOS) in Supplementary Fig. 11. Moreover, the sizable $\mathrm{Te}-\mathrm{Te}$ hybridization accounts for the emergence of the three-dimensionality of the Fermi surface. Interestingly, the calculated DOS for the dummy 'host' material $1 \mathrm{~T}-\mathrm{Ti}_{2} \mathrm{PTe}_{2}$ share similar features with those of $3 \mathrm{R}-\mathrm{Ti}_{2} \mathrm{PTe}_{2}$, such as a pseudogap structure (valley) just above the Fermi energy (Fig. 4), naively implying that electron doping up to the pseudogap possibly stabilizes the intercalated phases within a rigid band picture.

Total energy calculations for $\mathrm{Zn}_{x} \mathrm{Ti}_{2} \mathrm{PTe}_{2}$ with different $\mathrm{Zn}$ concentrations $(0 \leq x \leq 1)$, intercalation sites (tetrahedral or octahedral) and 'host' structures (3R or $1 \mathrm{~T}$ ) provide useful information on the phase stability of the present system (see Fig. 4). Calculated heats of formation $E_{\mathrm{f}}=E\left(1 \mathrm{~T}-\mathrm{Zn}_{x} \mathrm{Ti}_{2} \mathrm{PTe}_{2}\right)-$ $E\left(3 \mathrm{R}-\mathrm{Ti}_{2} \mathrm{PTe}_{2}\right)-x E(\mathrm{Zn})$ in the $1 \mathrm{~T}$ phase show very small positive values (in the order of $10 \mathrm{meV}$ ) up to $x=0.5$, implying that an entropic term may stabilize the telluride upon intercalation of $\mathrm{Zn}$. This dopant level is fairly consistent with the experimentally obtained value of $\sim 0.4$. Further electron doping beyond the pseudogap results in the appearance of a peak around the Fermi energy (see the $x=1$ case in Fig. 4), indicating non-bonding electrons. On the other hand, the $\mathrm{Zn}$ intercalation in the $3 \mathrm{R}$ phase gives rise to a much larger $E_{\mathrm{f}}$ (in the order of $100 \mathrm{meV}$ ) even with a small dopant concentration such as $x=1 / 3$, and the DOS exhibit a peak structure around the Fermi energy as shown in Fig. 4, indicative of the deviation from the rigid band picture. The DOS peak is composed mainly of Ti- $d$ and $\mathrm{Zn}-s$ orbitals, preventing the $\mathrm{Zn}$ intercalation. As for $\mathrm{Zn}_{x} \mathrm{Zr}_{2} \mathrm{PTe}_{2}$, qualitative features in the calculated electronic structure are quite similar to $\mathrm{Zn}_{x} \mathrm{Ti}_{2} \mathrm{PTe}_{2}$, showing even smaller (still positive) heats of formation in the $1 \mathrm{~T}$ phase.

To obtain further insight into the metal selectivity, we performed the first principles calculations for $1 \mathrm{~T}-M_{0.25} \mathrm{Ti}_{2} \mathrm{PTe}_{2}$ $(M=\mathrm{Cr}, \mathrm{Mn}, \mathrm{Fe}, \mathrm{Co}, \mathrm{Ni}, \mathrm{Cu}, \mathrm{Zn}$ and $\mathrm{Cd})$ and $1 \mathrm{~T}-M_{0.25} \mathrm{Zr}_{2} \mathrm{PTe}_{2}$ $(M=\mathrm{Ni}, \mathrm{Cu}, \mathrm{Zn}$ and $\mathrm{Cd})$ with $M$ sitting on the tetrahedral interstitial site, and estimated the heat of formation, defined as $E_{\mathrm{f}}=E\left(1 \mathrm{~T}-M_{0.25} \mathrm{Ti}_{2} \mathrm{PTe}_{2}\right)-E\left(3 \mathrm{R}-\mathrm{Ti}_{2} \mathrm{PTe}_{2}\right)-0.25 E(M)$. As shown in Fig. 5, a positive but very small value of $E_{\mathrm{f}}$ for $\mathrm{Zn}$ intercalated both in $\mathrm{Ti}_{2} \mathrm{PTe}_{2}$ and $\mathrm{Zr}_{2} \mathrm{PTe}_{2}$ is clearly seen, while marginally small values are achieved for $M=\mathrm{Ni}, \mathrm{Cu}$ and $\mathrm{Cd}$ compared with the intercalated systems with $M=\mathrm{Cr}, \mathrm{Mn}, \mathrm{Fe}$ and $\mathrm{Co}$, which reasonably confirms the experimentally observed metal selectivity. These results demonstrate that the thermodynamic stability of the intercalated compound is the decisive factor in determining the selectivity. We note that unintercalated Ni has

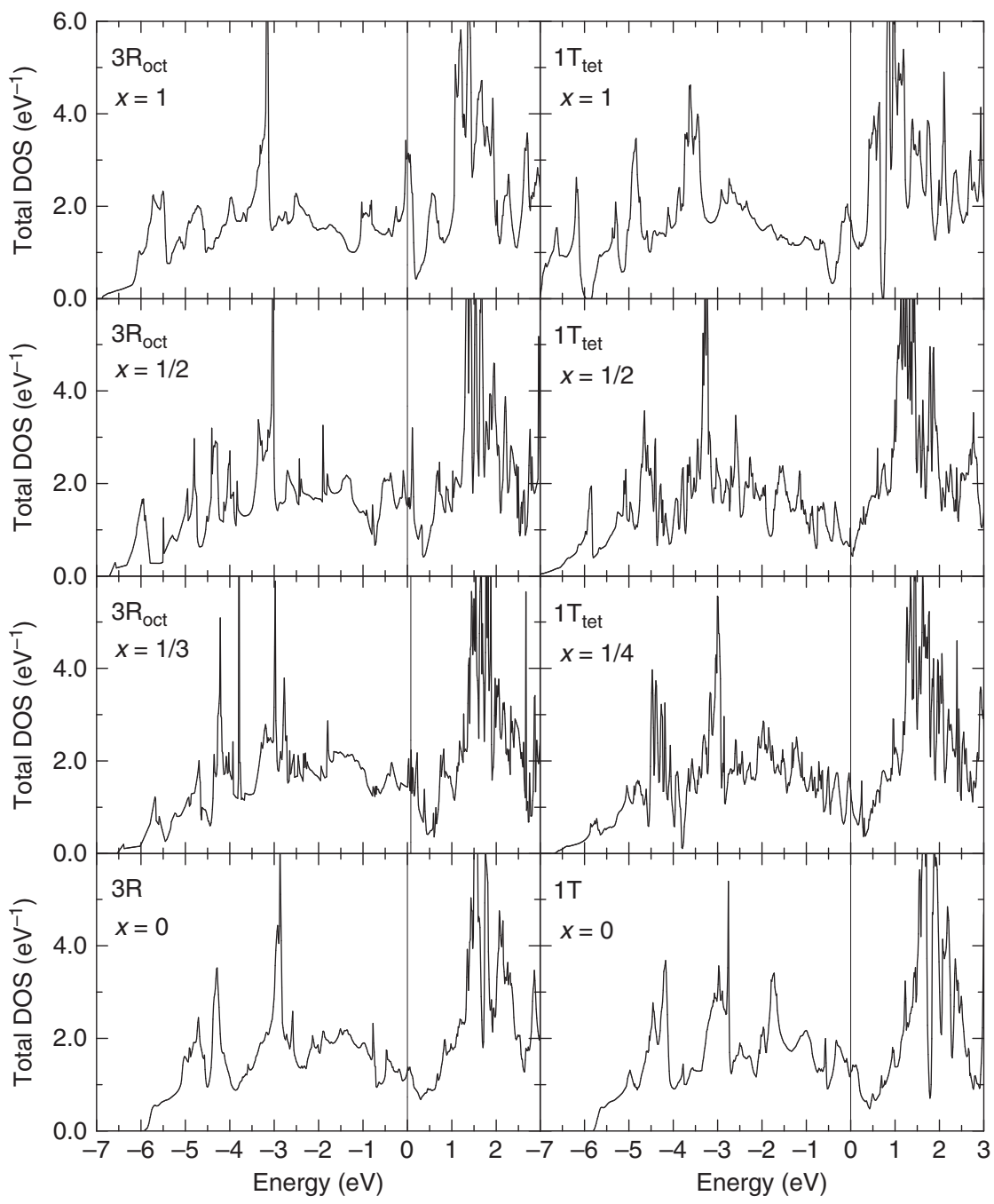

Figure 4 | Calculated total density of states of $\mathbf{Z n}_{\mathbf{x}} \mathbf{T i}_{\mathbf{2}} \mathbf{P T e} \mathbf{e}_{\mathbf{2}}$ as a function of $\mathbf{Z n}$ concentration $\mathbf{x}$. Left: $3 R$-type $\mathrm{Zn}_{\mathbf{x}} \mathrm{Ti}_{2} \mathrm{PTe}_{2}$ with octahedral coordinate $\mathrm{Zn}$; and right: $1 T$-type $\mathrm{Zn}_{x} \mathrm{Ti}_{2} \mathrm{PTe}_{2}$ with tetrahedral coordinate $\mathrm{Zn}$. The Fermi energy is set to the origin of energy. 
similarly small values of $E_{\mathrm{f}}=+0.06 \mathrm{eV}\left(\mathrm{Ti}_{2} \mathrm{PTe}_{2}\right)$ and $+0.04 \mathrm{eV}$ $\left(\mathrm{Zr}_{2} \mathrm{PTe}_{2}\right)$, the reason of which is not clear but may be related to kinetic aspects of reactions (diffusion of metal, surface reactions and so on).

Towards practical reaction conditions. A remarkable aspect in $\mathrm{Ti}_{2} \mathrm{PTe}_{2}$ and $\mathrm{Zr}_{2} \mathrm{PTe}_{2}$ is the facile uptake of heavy metals at mild temperatures and in the solid state. We tested the effect of reaction temperature for $M=\mathrm{Zn}$ and $\mathrm{Cd}$, with a fixed reaction time of 48 h. Shown in Fig. 6 and Supplementary Fig. 12 is the fraction of the intercalated (1T) phase as a function of reaction temperature. In the case of $\mathrm{Ti}_{2} \mathrm{PTe}_{2}$, the volume fraction of $\mathrm{Cd}$-intercalated phase readily increases at temperatures above $50{ }^{\circ} \mathrm{C}$ and reaches almost $100 \%$ at $150{ }^{\circ} \mathrm{C}$. In contrast, a higher temperature of $200^{\circ} \mathrm{C}$ is necessary to attain a full uptake of $\mathrm{Zn}$. The $\mathrm{Zr}_{2} \mathrm{PTe}_{2}$ system has quantitatively a similar tendency in intercalation behaviour, but the required temperatures, $190^{\circ} \mathrm{C}$ (Cd) and $220^{\circ} \mathrm{C}(\mathrm{Zn})$, are higher than those in $\mathrm{Ti}_{2} \mathrm{PTe}_{2}$. In $\mathrm{Ti}_{2} \mathrm{PTe}_{2}, \mathrm{Cu}$ requires $300^{\circ} \mathrm{C}$ and $\mathrm{Fe}$ and $\mathrm{Mn}$ requires $>400^{\circ} \mathrm{C}$, given that the same reaction period of $48 \mathrm{~h}$ is applied. Furthermore, the reaction of $\mathrm{Zr}_{2} \mathrm{PTe}_{2}$ with $\mathrm{Cu}$ at $70{ }^{\circ} \mathrm{C}$ for 20 days yielded a single phase of $1 \mathrm{~T}-\mathrm{Cu}_{x} \mathrm{Zr}_{2} \mathrm{PTe}_{2}$ (Supplementary Fig. 13). These results suggest that this type of intercalation could be

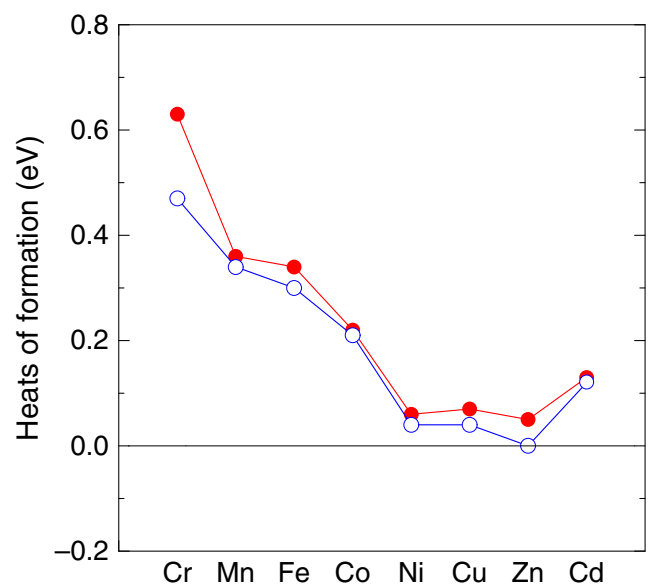

Figure 5 | Calculated heats of formation per formula unit in

$\boldsymbol{M}_{\mathbf{0 . 2 5}} \mathbf{T}_{\mathbf{2}} \mathbf{P T e}_{\mathbf{2}}(\boldsymbol{T}=\mathbf{T i}, \mathbf{Z r})$. The heat of formation was defined as $E_{\mathrm{f}}=E\left(1 \mathrm{~T}-\mathrm{M}_{0.25} \mathrm{~T}_{2} \mathrm{PTe} \mathrm{Te}_{2}\right)-E\left(3 \mathrm{R}-\mathrm{T}_{2} \mathrm{PTe} \mathrm{Te}_{2}\right)-0.25 E(\mathrm{M})$, where $T=\mathrm{Ti}$ (red) and $\mathrm{Zr}$ (blue); $\mathrm{M}=\mathrm{Cr}, \mathrm{Mn}, \mathrm{Fe}, \mathrm{Co}, \mathrm{Ni}, \mathrm{Cu}, \mathrm{Zn}$ and $\mathrm{Cd}$. further expanded, with a versatile potential to control the reactivity and selectivity.

\section{Discussion}

The difference in the intercalation temperature makes $\mathrm{Ti}_{2} \mathrm{PTe}_{2}$ and $\mathrm{Zr}_{2} \mathrm{PTe}_{2}$ of interest as adsorbents to chemically separate $\mathrm{Cd}$ from other metals simply by tailoring the temperature. In many forms, Cd has been (or was) widely used and discharged from the electroplating industry, electrical contact devices, nickel cadmium batteries and pigments ${ }^{44,45}$. Traditional metal separation procedures (smelting, precipitation, ion exchange and solvent extraction) are solution-based ${ }^{46}$. As shown in Supplementary Figs 14 and 15, test reactions of $\mathrm{Ti}_{2} \mathrm{PTe}_{2}$ with an equimolar mixture of Cd-Mn at $100{ }^{\circ} \mathrm{C}$ for $96 \mathrm{~h}$ and $\mathrm{Cd}-\mathrm{Ti}$ at $300^{\circ} \mathrm{C}$ for $48 \mathrm{~h}$ yielded only the $\mathrm{Cd}$ intercalated material. Selective intercalation of Cd-containing alloys might also be possible. Reactions with commercially available alloys, $\mathrm{Cu}_{0.75} \mathrm{~Pb}_{0.25}$ and $\mathrm{Cu}_{0.80} \mathrm{Sn}_{0.20}$, at $300{ }^{\circ} \mathrm{C}, 48 \mathrm{~h}$ resulted in only $\mathrm{Cu}$ accommodation into $\mathrm{Ti}_{2} \mathrm{PTe}_{2}$ as shown in Supplementary Fig. 16. The present solution-free approach may find a new route for capturing $\mathrm{Cd}$ and other toxic elements. It is noteworthy that the vacuum environment is not a requirement; reactions in ambient conditions yielded the same result (see Supplementary Fig. 17). What we showed here is a prototype application in environmental remediation. Given the fact that all the current technologies for metal capturing are based on solution chemistry, our demonstration of the selective solid-state metal capturing (in particular, the Cd capturing above $80{ }^{\circ} \mathrm{C}$ for $\mathrm{Ti}_{2} \mathrm{PTe}_{2}$ ) is the first of its kind in inorganic layered materials, opening new possibilities for applications to solve environmental issues.

In addition, the observed reactivity and highly mobile nature of the heavy metals at very low temperatures suggests a possibility to develop multivalent ion conductors at significantly lowered working temperatures. This compound represents a member of a larger structure family as in $\mathrm{Ta}_{2} \mathrm{CS}_{2}$, with possibilities for improved performance as well as new properties. We believe that layered compounds with less electronegative anions such as telluride and antimonide could provide fertile ground for the development of exotic functionalities.

\section{Methods}

Materials synthesis. The stoichiometric polycrystalline samples of the host material $\mathrm{Ti}_{2} \mathrm{PTe}_{2}$ and $\mathrm{Zr}_{2} \mathrm{PTe}_{2}$ were prepared by the conventional solid state reaction method with excess $\mathrm{P}$ to compensate its loss due to sublimation above $500^{\circ} \mathrm{C}$. Ti/Zr (Kojundo Chemical, 3N), P (Kojundo Chemical, 2N) and Te
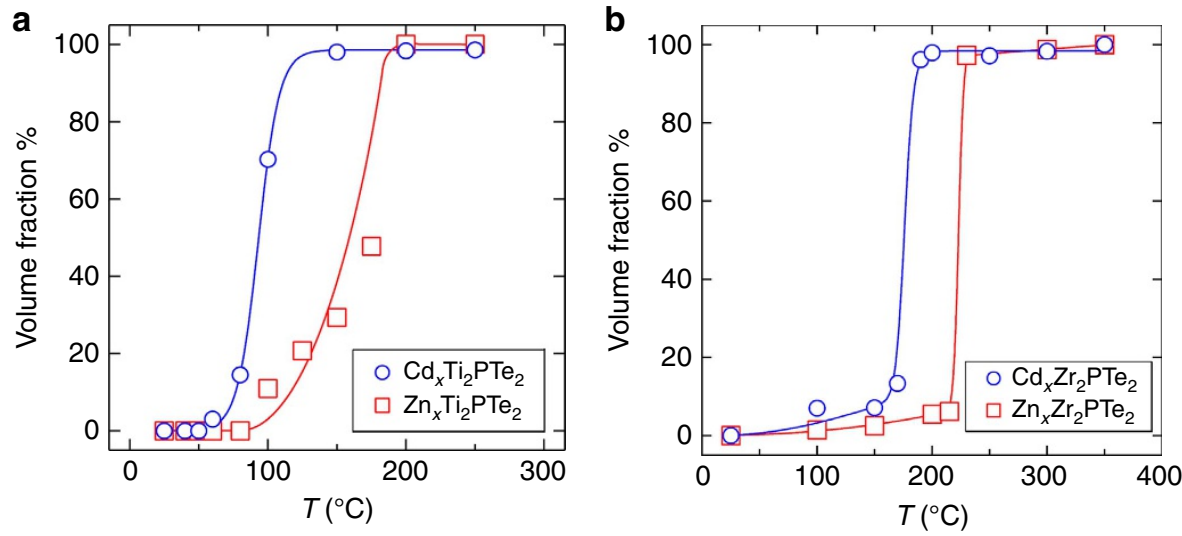

Figure 6 | Temperature-dependent intercalation yields for $\mathbf{T i}_{\mathbf{2}} \mathbf{P} \mathbf{T e}_{\mathbf{2}}$ and $\mathbf{Z r}_{\mathbf{2}} \mathbf{P} \mathbf{P T}_{\mathbf{2}}$. Reaction temperature dependence of the volume fraction of (a) $M_{x} T_{2} \mathrm{PTe}_{2}$ and (b) $M_{x} Z r_{2} \mathrm{PTe}_{2}$ where $M=\mathrm{Zn}$ (red) and $\mathrm{Cd}$ (blue). Both the samples were heated together with and elemental metal ( $\mathrm{Zn}$ or $\mathrm{Cd}$ ) at various temperatures for $48 \mathrm{~h}$. The molar volume fraction was estimated from the Rietveld refinement. Solid lines are drawn as a guide for visualization. The error bars are smaller than the size of the symbols. 
(Kojundo Chemical, 3N) powders were mixed in the molar ratio of 2: 1.1: 2 and pelletized in a nitrogen-filled glove box. The obtained pellet was sealed into an evacuated silica tube $\left(<10^{-2} \mathrm{~Pa}\right)$ and heated to $850^{\circ} \mathrm{C}$ at a rate of $20^{\circ} \mathrm{Ch}^{-1}$, and annealed for $24 \mathrm{~h}$. To ensure full incorporation of both phosphorus and tellurium, a slow cooling rate of $2{ }^{\circ} \mathrm{Ch}^{-1}$ was applied from 850 to $400^{\circ} \mathrm{C}$ before rapid cooling to room temperature.

The low temperature reactions of $\mathrm{Ti}_{2} \mathrm{PTe}_{2}$ and $\mathrm{Zr}_{2} \mathrm{PTe}_{2}$ with various elemental metals $(M=\mathrm{Li}, \mathrm{Na}, \mathrm{Mg}, \mathrm{Al}, \mathrm{Si}, \mathrm{K}, \mathrm{Ca}, \mathrm{Sc}, \mathrm{Ti}, \mathrm{V}, \mathrm{Cr}, \mathrm{Mn}, \mathrm{Fe}, \mathrm{Co}, \mathrm{Ni}, \mathrm{Cu}, \mathrm{Zn}, \mathrm{Ga}, \mathrm{Ge}$, $\mathrm{Sr}, \mathrm{Y}, \mathrm{Zr}, \mathrm{Nb}, \mathrm{Mo}, \mathrm{Ru}, \mathrm{Pd}, \mathrm{Ag}, \mathrm{Cd}$, In, Sn, Hf, Ta, Ir, Hg, Pb) were performed in the solid state. $\mathrm{Ti}_{2} \mathrm{PTe}_{2}$ and the metal powder as received (Kojundo Chemical, $4 \mathrm{~N}$ ) were mixed with various molar ratios (typically $1: 1$ ) and pelletized in a nitrogenfilled glove box. The pellet was sealed in an evacuated silica tube $\left(<10^{-2} \mathrm{~Pa}\right)$ and heated at temperatures between $100^{\circ} \mathrm{C}$ and $400^{\circ} \mathrm{C}$ for $48-96 \mathrm{~h}$. Reactions with equimolar mixtures of $\mathrm{Cd}$ and $\mathrm{Ti}$ and of $\mathrm{Cd}$ and $\mathrm{Mn}$ in $\mathrm{Ti}_{2} \mathrm{PTe}_{2}$ were conducted, respectively, at $300^{\circ} \mathrm{C}$ for $48 \mathrm{~h}$, and at $100^{\circ} \mathrm{C}$ for $96 \mathrm{~h}$. Also, reactions with $\mathrm{Cu}_{0.75} \mathrm{~Pb}_{0.25}$ alloy and with $\mathrm{Cu}_{0.80} \mathrm{Sn}_{0.20}$ alloy (Kojundo Chemical, $3 \mathrm{~N}$ ) were performed at $300^{\circ} \mathrm{C}$ for $48 \mathrm{~h}$. Furthermore, for lithium intercalation, $1 \mathrm{M} n$-butyl lithium solution in hexane was used and the reaction allowed to proceed for $72 \mathrm{~h}$. Deintercalation of $\mathrm{Zn}$ was performed at room temperature by mixing $\mathrm{Zn}_{0.4} \mathrm{Ti}_{2} \mathrm{PTe}_{2}$ with $\mathrm{I}_{2}$ dissolved in acetonitrile at the molar ratio of 1: 1 for 2 days.

X-ray and neutron diffraction. Laboratory powder X-ray diffraction were collected using a Bruker D8 diffractometer with $\mathrm{Cu} K_{\alpha}$ radiation. The diffraction data for structural refinement were recorded in a $2 \theta$ range from $5^{\circ}$ to $80^{\circ}$ with a step interval of $0.02^{\circ}$. The diffraction pattern for $\mathrm{Ti}_{2} \mathrm{PTe}_{2}$ was fit using the space group $R-3 m$ and the cell parameters $a=3.63949(6) \AA$ and $c=28.4885(4) \AA$, in agreement with reported values in the literature ${ }^{27}$. High resolution synchrotron $\mathrm{X}$-ray diffraction experiments were performed on $\mathrm{Zn}_{x} \mathrm{Ti}_{2} \mathrm{PTe}_{2}, \mathrm{Cu}_{x} \mathrm{Ti}_{2} \mathrm{PTe}_{2}$, $\mathrm{Zn}_{x} \mathrm{Zr}_{2} \mathrm{PTe}_{2}$ and $\mathrm{Cd}_{x} \mathrm{Zr}_{2} \mathrm{PTe}_{2}$ at room temperature on a Debye-Scherrer camera installed at beamline BL02B2, SPring- 8 . The incident beam from a bending magnet was monochromatized to $0.35479(1) \AA$. The powder samples were loaded into a glass capillary $(0.1 \mathrm{~mm}$ inner diameter) and rotated during measurements to reduce preferential orientation. The diffraction data were recorded in a $2 \theta$ range from $0^{\circ}$ to $60^{\circ}$ with a step interval of $0.01^{\circ}$. Powder neutron diffraction measurements were carried out at room temperature on an approximately $2 \mathrm{~g}$ sample at BT- 1 $(\lambda=1.5403 \AA)$, National Institute of Standards and Technology.

Structural analysis. The obtained X-ray and neutron data were analysed by the Rietveld method using the RIETAN-FP program ${ }^{47}$. The agreement indices used were $R_{\mathrm{p}}=\Sigma\left|y_{\mathrm{io}}-y_{\mathrm{ic}}\right| / \Sigma y_{\mathrm{io}}, R_{\mathrm{wp}}=\left[\Sigma w_{\mathrm{i}}\left(y_{\mathrm{io}}-y_{\mathrm{ic}}\right)^{2} / \Sigma w_{\mathrm{i}}\left(y_{\mathrm{io}}\right)^{2}\right]^{1 / 2}$ and the goodness of fit, $\chi^{2}=\left[R_{\mathrm{wp}} / R_{\exp }\right]^{2}$ where $R_{\exp }=\left[(N-P) / \Sigma w_{\mathrm{i}} y_{\mathrm{io}}^{2}\right]^{1 / 2}, y_{\mathrm{io}}$ and $y_{\mathrm{ic}}$ are the observed and calculated intensities, $w_{\mathrm{i}}$ is the weighting factor, $N$ is the total number of $y_{\mathrm{io}}$ data when the background is refined and $P$ is the number of adjusted parameters. The energy dispersive X-ray spectroscopy (EDX) measurements were performed using an Oxford Instruments IE-250 detector attached to a scanning electron microscope (SEM, HITACHI S-3400N). For each composition, 10-40 randomly selected spots were examined.

For X-ray absorption spectroscopy (XAS) measurements, $\mathrm{Zn}_{04} \mathrm{Ti}_{2} \mathrm{PTe}_{2}$ was homogeneously dispersed in dried boron nitride powder and pelletized. Zn $K$-edge spectra were recorded in transmission mode at beam line BL01B1 in SPring-8, Japan with a double-crystal $\mathrm{Si}(111)$ monochrometer. The energy scale was calibrated using $\mathrm{Cu}$ foil. Data were collected at room temperature. Extended X-ray absorption fine structure (EXAFS) analysis was performed using REX2000 data analysis software, with the theoretical backscattering phases and amplitudes calculated with the code FEFF8 (ref. 48). Radial structure functions were obtained using Fourier transformation of the oscillations between 3.0 and $14.0 \AA$. To obtain local structural parameters, inverse Fourier transforms were calculated from the radial structure functions between 1.688 and $2.700 \AA$. Curve fitting was performed in $k$ space.

First principles calculations. First principles density functional theory calculations are performed with all-electron full-potential linearized augmented plane wave method in the scalar-relativistic scheme. Fractional intercalation is simulated by assuming super cell models appropriate to given concentrations. Lattice constants and internal atomic positions are fully optimized by calculating total energy and atomic forces with preserving the original crystal symmetry.

Data availability. The data that support the findings of this study are available from the corresponding author upon request.

\section{References}

1. Blanchard, G., Maunaye, M. \& Martin, G. Removal of heavy metals from waters by means of natural zeolites. Water. Res. 18, 1501-1507 (1984).

2. Lee, K. S., Seo, D. K. \& Whangbo, M. H. Electronic band structure study of the anomalous electrical and superconducting properties of hexagonal alkali tungsten bronzes $\mathrm{A}_{\mathrm{x}} \mathrm{WO}_{3}(\mathrm{~A}=\mathrm{K}, \mathrm{Rb}, \mathrm{Cs})$. J. Am. Chem. Soc. 119, 4043-4049 (1997).
3. Dresselhaus, M. S. \& Dresselhaus, G. Intercalation compounds of graphite. $A d v$. Phys. 51, 1-186 (2002).

4. Goodenough, J. B. \& Park, K. S. The Li-ion rechargeable battery: a perspective. J. Am. Chem. Soc. 135, 1167-1176 (2013).

5. Takada, K. et al. Superconductivity in two-dimensional $\mathrm{CoO}_{2}$ layers. Nature 422, 53-55 (2003).

6. Yamanaka, S., Hotehama, K. I. \& Kawaji, H. Superconductivity at $25.5 \mathrm{~K}$ in electron-doped layered hafnium nitride. Nature 392, 580-582 (1998).

7. Sasaki, S. et al. Topological superconductivity in $\mathrm{Cu}_{\mathrm{x}} \mathrm{Bi}_{2} \mathrm{Se}_{3}$. Phys. Rev. Lett. 107, 217001 (2011).

8. Bruce, D. W. \& O’Hare, D. Inorg. Mater. (Wiley, 1996).

9. Yamanaka, S. Intercalation and superconductivity in ternary layer structured metal nitride halides (MNX: $\mathrm{M}=\mathrm{Ti}, \mathrm{Zr}, \mathrm{Hf} ; \mathrm{X}=\mathrm{Cl}, \mathrm{Br}$, I). J. Mater. Chem. 20, 2922-2933 (2010).

10. Whittingham, M. S. Chemistry of intercalation compounds: metal guests in chalcogenide hosts. Prog. Solid State Chem. 12, 41-99 (1978).

11. Clement, R. A novel route to intercalation into layered $\mathrm{MnPS}_{3}$. J. Chem. Soc. Chem. Commun. 14, 647-648 (1980).

12. Herber, R. H. \& Maeda, Y. Intercalation compounds of iron (III) oxychloride systematics of nitrogen-containing Lewis base intercalants. Inorg. Chem. 20, 1409-1415 (1981).

13. Rouxel, J. in Intercalated Layered Materials 201-250 (Springer, 1979).

14. Lerf, A. \& Schöllhorn, R. Solvation reactions of layered ternary sulfides $A_{x} T i S_{2}$, $\mathrm{A}_{\mathrm{x}} \mathrm{NbS}_{2}$, and $\mathrm{A}_{\mathrm{x}} \mathrm{TaS}_{2}$. Inorg. Chem. 16, 2950-2956 (1977).

15. Omloo, W. P. F. A. M. \& Jellinek, F. Intercalation compounds of alkali metals with niobium and tantalum dichalcogenides. J. Less Common Metals 20, 121-129 (1970).

16. Di Salvo, F. J., Hull, Jr G. W., Schwartz, L. H., Voorhoeve, J. M. \& Waszczak, J. V. Metal intercalation compounds of $\mathrm{TaS}_{2}$ : preparation and properties. J. Chem. Phys. 59, 1922-1929 (1973).

17. Gamble, F. R., Osiecki, J. H. \& DiSalvo, F. J. Some superconducting intercalation complexes of $\mathrm{TaS}_{2}$ and substituted pyridines. J. Chem. Phys. 55, 3525-3530 (1971).

18. Schöllhorn, R. \& Zagefka, H. D. Demonstration of the ionic structure of the intercalation compound $\mathrm{TaS}_{2} \mathrm{NH}_{3}$. Angew. Chem. Int. Ed. 16, 199-200 (1977).

19. Schöllhorn, R. Intercalation chemistry. Physica B C 99, 89-99 (1980).

20. Shannon, M. A. et al. Science and technology for water purification in the coming decades. Nature 452, 301-310 (2008).

21. Huang, C. P. \& Blankenship, D. W. The removal of mercury (II) from dilute aqueous solution by activated carbon. Water. Res. 18, 37-46 (1984).

22. Benhammou, A., Yaacoubi, A., Nibou, L. \& Tanouti, B. Adsorption of metal ions onto Moroccan stevensite: kinetic and isotherm studies. J. Colloid Interface Sci. 282, 320-326 (2005).

23. Kesraoui-Ouki, S., Cheeseman, C. R. \& Perry, R. Natural zeolite utilisation in pollution control: a review of applications to metals' effluents. J. Chem. Technol Biotechnol. 59, 121-126 (1994).

24. Manos, M. J., Ding, N. \& Kanatzidis, M. G. Layered metal sulfides: exceptionally selective agents for radioactive strontium removal. Proc. Natl Acad. Sci. USA 105, 3696-3699 (2008).

25. Manos, M. J. \& Kanatzidis, M. G. Sequestration of heavy metals from water with layered metal sulfides. Chem. Eur. J. 15, 4779-4784 (2009).

26. Ding, N. \& Kanatzidis, M. G. Selective incarceration of caesium ions by Venus flytrap action of a flexible framework sulfide. Nat. Chem 2, 187-191 (2010).

27. Allred, A. L. Electronegativity values from thermochemical data. J. Inorg. Nucl. Chem. 17, 215-221 (1961).

28. Baranov, N. V. et al. Ferromagnetism and structural transformations caused by Cr intercalation into $\mathrm{TiTe}_{2}$. J. Phys. Condens. Matter 21, 506002 (2009).

29. Kamitani, M. et al. Superconductivity in $\mathrm{Cu}_{\mathrm{x}} \mathrm{IrTe}_{2}$ driven by interlayer hybridization. Phys. Rev. B 87, 180501 (2013).

30. Philipp, F., Schmidt, P., Milke, E., Binnewies, M. \& Hoffmann, S. Synthesis of the titanium phosphide telluride $\mathrm{Ti}_{2} \mathrm{PTe}_{2}$ : a thermochemical approach. J. Solid State Chem. 181, 758-767 (2008).

31. Philipp, F., Schmidt, P., Ruck, M., Schnelle, W. \& Isaeva, A. The layered metal $\mathrm{Ti}_{2} \mathrm{PTe}_{2}$. J. Solid State Chem. 181, 2859-2863 (2008).

32. Beckmann, O., Boller, H. \& Nowotny, H. Die Kristallstrukturen von $\mathrm{Ta}_{2} \mathrm{~S}_{2} \mathrm{C}$ und $\mathrm{Ti}_{4} \mathrm{~S}_{5}\left(\mathrm{Ti}_{0.81} \mathrm{~S}\right)$. Monatsh. Chem. 101, 945-955 (1970).

33. Boller, H. \& Sobczak, R. Einlagerungsphasen vom $\mathrm{TypMe}_{\mathrm{x}}\left[\mathrm{Ta}_{2} \mathrm{~S}_{2} \mathrm{C}\right]$. Monatsh. Chem. 102, 1226-1233 (1971).

34. Brec, R., Ritsma, J., Ouvrard, G. \& Rouxel, J. Alkali metal intercalates of tantalum carbide sulfide. Inorg. Chem. 16, 660-665 (1977).

35. Suzuki, M., Suzuki, I. S. \& Walter, J. Magnetism and superconductivity in $\mathrm{M}_{\mathrm{c}} \mathrm{Ta}_{2} \mathrm{~S}_{2} \mathrm{C}(\mathrm{M}=\mathrm{Fe}, \mathrm{Co}, \mathrm{Ni}$, and $\mathrm{Cu})$. Phys. Rev. B 71, 224407 (2005).

36. Singh, H. P. \& Dayal, B. Lattice parameters and thermal expansion of zinc telluride and mercury selenide. Acta Cryst. A 26, 363-364 (1970).

37. Hahn, H., Frank, G., Klingler, W., Störger, A. D. \& Störger, G. Untersuchungen über ternäre Chalkogenide. VI. Über Ternäre Chalkogenide des Aluminiums, Galliums und Indiums mit Zink, Cadmium und Quecksilber. Z. Anorg. Allg. Chem. 279, 241-270 (1955). 
38. The Inorganic Crystal Structure Database (ICSD). http://www.fizinformationsdienste.de/en/DB/icsd/ index.html.

39. Patel, S. N. \& Balchin, A. A. Structural studies of lithium intercalated titanium di-telluride. J. Mater. Sci. Lett. 4, 382-384 (1985).

40. Shorikov, D. O., Titov, A. N., Titova, S. G. \& Tolochko, B. P. Structural parameters of intercalation compounds based on titanium dichalcogenides near the temperature of the polaronic band collapse. Nucl. Instrum. Methods Phys. Res. A 470, 215-218 (2001).

41. Yarmoshenko, Y. M. et al. Spatial dependence of the dichroism of photoemission of $\mathrm{Fe}_{1 / 4} \mathrm{TiTe}_{2}$ upon excitation with circularly polarized radiation. Phys. Solid State 50, 2190-2198 (2008).

42. Cybulski, Z., Feltz, A. \& Andratschke, M. Structure and properties of quaternary chalcogenides. Mater. Res. Bull. 24, 157-162 (1989).

43. Claessen, R. et al. Complete band-structure determination of the quasi-two-dimensional Fermi-liquid reference compound TiTe ${ }_{2}$. Phys. Rev. B 54, 2453-2465 (1996).

44. Salim, R., Al-Subu, M. M. \& Sahrhage, E. Uptake of cadmium from water by beech leaves. J. Environ. Sci. Health A27, 603-627 (1992).

45. Cheung, C. W., Porter, J. F. \& McKay, G. Elovich equation and modified second-order equation for sorption of cadmium ions onto bone char. J. Chem. Technol. Biotechnol. 75, 963-970 (2000).

46. Chang, Y. H., Hsieh, K. H. \& Chang, F. C. Removal of $\mathrm{Hg}^{2+}$ from aqueous solution using a novel composite carbon adsorbent. J. Appl. Polym. Sci. 112, 2445-2454 (2009).

47. Izumi, F. \& Momma, K. Three-dimensional visualization in powder diffraction. Solid State Phenom. 130, 15-20 (2007).

48. Rehr, J. J. \& Albers, R. C. Theoretical approaches to X-ray absorption fine structure. Rev. Mod. Phys. 72, 621-654 (2000).

\section{Acknowledgements}

The work was supported by CREST and JSPS KAKENHI (JP16H6439, JP16H6440, JP16H6441, JP16H02267). The early stage of the work was supported by FIRST. We thank C. Tassel (Kyoto University), J. Kim, N. Tsuji and A. Fujiwara (JASRI) for their help during the SPring- 8 experiments.

\section{Author contributions}

T.Yaj. and H.K. conceived and designed the study. M.K., W.Y., D.K. and Y.Z. performed the synthesis, laboratory X-ray diffraction and SEM/EDX experiments. M.K., W.Y., T.Yaj. and Y.K. obtained synchrotron X-ray diffraction, while M.A.G. and H.K. obtained the neutron data. The structural refinement was performed by T.Yam., T.Yaj., W.Y. and M.K. Y.O. and Y.U. obtained X-ray absorption spectra and analysed the data. T.O. conducted first principles calculations. All the authors discussed the results. Y.Z., T.Yaj., T.O. and H.K. wrote the manuscript, with comments from Y.K. M.K., Y.O., W.Y. and M.A.G.

\section{Additional information}

Supplementary Information accompanies this paper at http://www.nature.com/ naturecommunications

Competing financial interests: The authors declare no competing financial interests.

Reprints and permission information is available online at http://npg.nature.com/ reprintsandpermissions/

How to cite this article: Yajima, T. et al. Selective and low temperature transition metal intercalation in layered tellurides. Nat. Commun. 7, 13809 doi: 10.1038/ncomms13809 (2016).

Publisher's note: Springer Nature remains neutral with regard to jurisdictional claims in published maps and institutional affiliations.

(c) (i) This work is licensed under a Creative Commons Attribution 4.0 International License. The images or other third party material in this article are included in the article's Creative Commons license, unless indicated otherwise in the credit line; if the material is not included under the Creative Commons license, users will need to obtain permission from the license holder to reproduce the material. To view a copy of this license, visit http://creativecommons.org/licenses/by/4.0/

C) The Author(s) 2016 